\title{
Acute in vivo administration of a fish oil-containing emulsion improves post-ischemic cardiac function in n-3-depleted rats
}

\author{
S. PELTIER ${ }^{1,2}$, W.J. MALAISSE ${ }^{1}$, L. PORTOIS ${ }^{1}$, L. DEMAISON ${ }^{2}$, V. NOVEL-CHATE ${ }^{2}$, \\ J.M. CHARDIGNY ${ }^{3}$, J.L. SEBEDIO ${ }^{3}$, Y.A.CARPENTIER ${ }^{1}$ and X.M. LEVERVE ${ }^{2}$ \\ ${ }^{1}$ Laboratoire de Chirurgie Expérimentale L. Deloyers, Université Libre de Bruxelles, B-1070-Brussels, \\ Belgium; ${ }^{2}$ Laboratoire de Bioénergétique Fondamentale et Appliquée, INSERM E-0221, Université Joseph Fourier, \\ F-38041-Grenoble; ${ }^{3}$ Département Alimentation Humaine INRA, Site de Theix, St Genès Champanelle, France
}

Received March 23, 2006; Accepted May 30, 2006

\begin{abstract}
A novel i.v. lipid preparation (MCT:FO) containing $80 \%$ medium chain-triacylglycerols and $20 \%$ fish oil was recently developed to rapidly replenish cell membrane phospholipids with omega 3 (n-3) polyunsaturated fatty acids (PUFA). In regard of this property, we investigated the effect of a single i.v. administration of MCT:FO on the recovery of cardiac function after ischemia in control and n-3-depleted rats. Results were compared with those obtained either with a control preparation, where FO was replaced by triolein (MCT:OO), or with saline. Saline $(1 \mathrm{ml})$ or lipid preparation (also $1 \mathrm{ml}$ ) was injected as a bolus via the left saphenous vein. After $60 \mathrm{~min}$ the heart was removed and perfused for 20 min in normoxic conditions according to Langendorff. Thereafter, the heart was subjected to a 20 min zero-flow normothermic ischemia, followed by $40 \mathrm{~min}$ reperfusion. Cardiac mechanical and metabolic functions were monitored. In control rats, the previous administration of a lipid preparation (MCT:FO or MCT:OO) versus saline improved cardiac function during aerobic reperfusion post-ischemia. $\mathrm{N}$-3-depleted rats showed decreased basal cardiac function and impaired recovery following ischemia. However, the bolus injection of MCT:FO opposed the deleterious effect of longterm n-3-deficiency and, in this respect, was superior to MCT:OO over the first $20 \mathrm{~min}$ of reperfusion. This novel approach to rapidly correct n-3 PUFA-deficiency might be clinically relevant and offer interesting perspectives in the management of acute ischemic accidents.
\end{abstract}

Correspondence to: Professor Willy J. Malaisse, Laboratoire de Chirurgie Expérimentale L. Deloyers, Université Libre de Bruxelles, Avenue Joseph Wybran, 40, B-1070-Brussels, Belgium E-mail: malaisse@ulb.ac.be

Key words: omega 3-deficiency, lipid preparation, ischemiareperfusion, Langendorff

\section{Introduction}

Ischemic heart disease is the leading cause of death in the world and will probably remain at the top ranking of mortality causes in 2020 (1). Dietary choices may have a role in the prevention and causation of coronary heart diseases (CHD) and numerous studies have shown a relationship between high consumption of fatty fish oil and low mortality following CHD $(2,3)$. Even if the role of diet in promoting health and preventing disease is difficult to elucidate due to the complex network of nutrients and other ingredients (4), the beneficial effects of eicosapentaenoic (EPA) and docosahexaenoic (DHA) acids on CHD outcome have been largely documented. Dietary supplementation of EPA and DHA was shown to exert protective effects on cardiac function and to decrease the incidence and complications of cardiovascular diseases $(5,6)$. Unfortunately, the evolution of nutritional habits in Western populations is characterized by a substantial decrease of n-3 together with an increase of n-6 polyunsaturated fatty acids (PUFA) intake (7). Hence, current Western diets decrease the $\mathrm{n}-3 / \mathrm{n}-6$ ratio in cell membrane phospholipids.

One hypothesis to explain the cardioprotective effects of n-3 PUFA is via their incorporation into cardiac cell membrane phospholipids which induces a direct effect on voltage-gated ionic channels (8) and/or modifies intracellular calcium homeostasis (9). In some acute clinical situations such as myocardial infarction, it may be advantageous to rapidly modify the n-3 PUFA content in cardiac cell phospholipids; this may not be achieved by oral supplementation with fish oil which generally leads to a significant enrichment after 2 weeks (10). In a recent study on a limited number of patients, Schrepf et al have shown that intravenous (i.v.) administration of a lipid emulsion made of fish oil had a protective effect on severe cardiac arrhythmias (11). Nevertheless, since plasma clearance of this preparation is fairly slow and requires low infusion rate, anti-arrhythmic effects may not be expected before 4-6 h (11). To accelerate the process, new lipid preparations were developed to rapidly correct n-3 PUFA deficiency by incorporation of these fatty acids in cell membranes. As recently shown, a single i.v. injection of this novel lipid 
Table I. Fatty acid pattern (ponderal percentage) of lipids in the diets.

\begin{tabular}{lcc}
\hline Diet & Control & n-3-depleted \\
\hline C16:0 (\%) & $13.4-13.8^{\mathrm{a}}$ & $17.5-19.7$ \\
$\mathrm{C} 16: 1 \mathrm{n}-7(\%)$ & $0.6-0.8$ & $0.3-0.4$ \\
$\mathrm{C} 18: 0(\%)$ & $2.3-2.6$ & $9.8-11.3$ \\
$\mathrm{C} 18: 1 \mathrm{n}-9(\%)$ & $16.7-17.7$ & $42.1-45.0$ \\
$\mathrm{C} 18: 2 \mathrm{n}-6(\%)$ & $54.1-54.8$ & $12.8-20.7$ \\
$\mathrm{C} 18: 3 \mathrm{n}-6(\%)$ & $\mathrm{ND}^{\mathrm{b}}$ & $0.2-0.3$ \\
$\mathrm{C} 18: 3 \mathrm{n}-3(\%)$ & $5.9-6.4$ & $0.2-0.3$ \\
$\mathrm{C} 20: 1 \mathrm{n}-9(\%)$ & $0.9-0.9$ & $0.4-0.5$ \\
$\mathrm{C} 20: 3 \mathrm{n}-6(\%)$ & $0.0-0.1$ & $0.6-0.6$ \\
$\mathrm{C} 20: 4 \mathrm{n}-6(\%)$ & $0.2-0.2$ & $0.3-0.3$ \\
C20:5 n-3 (\%) & $0.6-0.8$ & $0.2-0.6$ \\
$\mathrm{C} 22: 4 \mathrm{n}-6(\%)$ & $0.2-0.2$ & $0.4-0.5$ \\
$\mathrm{C} 22: 5 \mathrm{n}-3(\%)$ & $0.1-0.2$ & $0.2-0.2$ \\
$\mathrm{C} 22: 6 \mathrm{n}-3(\%)$ & $1.4-1.6$ & $0.6-0.7$ \\
\hline
\end{tabular}

${ }^{\mathrm{a}}$ Lower and upper limit of separate determinations $(\mathrm{n}=2) .{ }^{\mathrm{b}} \mathrm{ND}$, not detected.

preparation (MCT:FO) containing $80 \%$ medium chaintriacylglycerols and $20 \%$ fish oil (with $0.4 \%$ (w/v) $\alpha$-tocopherol) increases within $60 \mathrm{~min}$ the $\mathrm{n}-3$ PUFA content of blood leucocyte and platelet phospholipids in healthy volunteers (12). The same pattern was observed in several tissues in animal studies (unpublished data). The purpose of the present study was to investigate whether a bolus i.v. administration of MCT:FO preparation 60-min before heart removal can improve the ability of cardiac muscle to recover its function after an ischemic period in isolated perfused rat hearts. The results were compared to those obtained after i.v. injection of either a control preparation (MCT:OO) with $80 \%$ medium chain-triacylglycerols and $20 \%$ triolein, or saline. Since the $n-3 / n-6$ ratio is high in laboratory animals fed regular chow diets, experiments were also conducted in animals depleted of n-3 PUFA for 2 generations. The experimental design also allowed, in animals injected with saline, to document the effect of long-term n-3 PUFA deficiency on cardiac function. To our knowledge, no previous information is available on the possible effects of long-term n-3 PUFA deficiency upon basal cardiac function and the ability of cardiac muscle to recover after an ischemic episode.

\section{Materials and methods}

Animal model. The present study was carried out in accordance with the French Government guidelines for the care and use of laboratory animals. Animals were housed in an animal quarter with control of temperature $\left(24^{\circ} \mathrm{C}\right)$, hygrometry $(60 \%)$ and brightness/darkness cycle $(12 \mathrm{~h} / 12 \mathrm{~h})$. Two groups of animals were used for this study. The first group (control animals) was composed of 24 male Wistar rats (14 weeks old, 400-550 g body weight) fed a commercially available chow diet (A03; Usine d'Alimentation Rationnelle, Epinay-surOrge, France). The second group of thirty-four male Wistar rats (14 weeks old, $450-550 \mathrm{~g}$ body weight) was fed a $\mathrm{n}-3$ PUFA deficient diet (n-3-depleted animals). These animals were issued from two generations of rats fed the n-3 PUFA deficient diet (13). All animals had ad libitum access to food and water.

The control diet contained (g/kg diet) 189 protein, 400 carbohydrate (including 38\% starch), 40 lipid (soya oil cake), 32 cellulose, 46 of a vitamin and mineral mixture and 97 water. The n-3 PUFA deficient diet contained (g/kg diet) 230 casein, 360 cornstarch, 260 saccharose, 50 sunflower oil, 20 agar-agar, 20 cellulose, 50 of vitamin mixture and 10 of mineral mixture. The fatty acid pattern of both diets is documented in Table I. The C18:3 n-3 weight percentage was $\sim 25$ times lower in the n-3 PUFA deficient than in the control diet. Other differences included higher C16:0, C18:0 and C18:1 n-9 and lower C18:2 n-6 relative content in the n-3 PUFA deficient compared to the control diet.

Lipid preparations. Both MCT:FO and MCT:OO lipid preparations were manufactured by B. Braun Melsungen AG (Melsungen, Germany). The fatty acid pattern of these preparations is shown in Table II. The total fatty acyl content of triacylglycerols was comparable between the two preparations, amounting $174.1 \pm 3.7 \mathrm{mg} / 1$. The most abundant fatty acids in the triacylglycerols were C8:0 $(49.2 \pm 3.7 \%)$ and C10:0 (34.5 $\pm 0.4 \%)$. The n-3 PUFAs C20:5 n-3, C22:5 n-3 and C22:6 n-3 amounted to $8.4 \%$ in the triacylglycerols of the MCT:FO preparation, while being undetected in the triacylglycerols of the MCT:OO preparation. Inversely, the weight percentage of C18:1 n-9 (15.5 versus $0.9 \%)$ and C18:2 n-6 (2.6 versus $0.1 \%$ ) was much higher in the triacylglycerols of the MCT:OO preparation as compared to those of the MCT:FO preparation.

The total fatty acyl content of phospholipids averaged $8.9 \pm 0.5 \mathrm{mg} / \mathrm{ml}$. Only minor differences in the weight percentage of C8:0, C10:0 and C20:5 n-3 were found in the phospholipids of the two preparations. The most abundant fatty acids in the phospholipids were C16:0 (32.2 $\pm 0.1 \%)$,

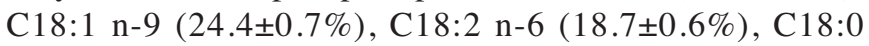

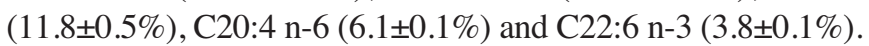

The unesterified fatty acids only accounted for $0.5 \pm 0.1 \%$ of the total amount of fatty acids present in the two preparation, i.e. $190.7 \pm 1.5 \mathrm{mg} / \mathrm{ml}$. They consisted mainly of mediumchain fatty acids C8:0 (16.1 $\pm 0.7 \%)$ and C10:0 (12.0 $\pm 0.4 \%)$,

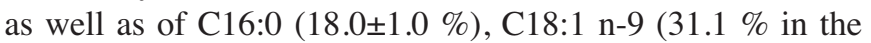
MCT:OO preparation and $21.8 \%$ in the MCT:FO preparation),

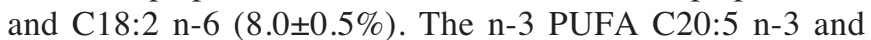
C22:5 n-3 represented, respectively, 4.3 and $5.8 \%$ of the total amount of unesterified fatty acids in the MCT:FO, whilst being undetectable in the unesterified fatty acids of the MCT:OO preparation.

Heart perfusion. The animals were anesthetized by intraperitoneal injection of pentobarbital sodium $(50 \mathrm{mg} / \mathrm{kg}$ body weight). One $\mathrm{ml}$ of lipid preparation (MCT:FO or MCT:OO) was injected via the left saphenous vein and the animals were positioned on a heating pad to maintain constant body temperature. After $60 \mathrm{~min}$, the animals were intravenously 
Table II. Fatty acid pattern of the MCT:00 and MCT:FO preparations.

\begin{tabular}{|c|c|c|c|c|c|c|c|c|}
\hline \multirow[b]{2}{*}{ Preparation lipids } & \multicolumn{4}{|c|}{ МCT:00 } & \multicolumn{4}{|c|}{ MCT:FO } \\
\hline & PL & $\mathrm{TG}$ & DG & NEFA & PL & TG & DG & NEFA \\
\hline Total (mg/ml) & 9.4 & 177.8 & 1.3 & 0.7 & 8.4 & 170.4 & 12.4 & 1.1 \\
\hline C8:0 (\%) & 0.7 & 45.5 & 28.2 & 16.7 & 0.2 & 52.8 & 14.4 & 15.4 \\
\hline $\mathrm{C} 10: 0(\%)$ & 0.3 & 34.1 & 30.8 & 12.4 & 0.1 & 34.8 & 9.6 & 11.6 \\
\hline $\mathrm{C} 12: 0(\%)$ & 0.0 & 0.3 & 0.0 & 0.0 & 0.0 & 0.6 & 0.1 & 0.4 \\
\hline $\mathrm{C} 14: 0(\%)$ & 0.3 & 0.0 & 0.0 & 6.1 & 0.2 & 0.1 & 0.4 & 3.8 \\
\hline $\mathrm{C} 16: 0(\%)$ & 32.3 & 0.9 & 0.0 & 17.0 & 32.1 & 0.4 & 1.9 & 18.9 \\
\hline C16:1 n-7 (\%) & 1.0 & 0.0 & 0.0 & 0.0 & 0.7 & 0.1 & 0.6 & 0.0 \\
\hline $\mathrm{C} 18: 0(\%)$ & 11.3 & 0.7 & 0.0 & 8.0 & 12.3 & 0.4 & 2.3 & 8.0 \\
\hline C18:1 n-9 (\%) & 25.1 & 15.5 & 32.8 & 31.1 & 23.7 & 0.9 & 5.6 & 21.8 \\
\hline C18:2 n-6 (\%) & 18.1 & 2.6 & 8.0 & 8.4 & 19.2 & 0.1 & 0.7 & 7.5 \\
\hline $\mathrm{C} 20: 0(\%)$ & 0.0 & 0.0 & 0.0 & 0.0 & 0.0 & 0.1 & 0.6 & 0.0 \\
\hline C18:3 n-3 (\%) & 0.0 & 0.0 & 0.0 & 0.0 & 0.0 & 0.0 & 0.5 & 0.0 \\
\hline C20:1 n-9 (\%) & 0.2 & 0.0 & 0.0 & 0.0 & 0.1 & 0.0 & 0.4 & 0.0 \\
\hline C18:4 n-3 (\%) & 0.0 & 0.0 & 0.0 & 0.0 & 0.0 & 0.2 & 1.1 & 0.0 \\
\hline C20:2 n-6 (\%) & 0.2 & 0.0 & 0.0 & 0.0 & 0.3 & 0.0 & 0.0 & 0.0 \\
\hline C20:3 n-6 (\%) & 0.3 & 0.1 & 0.0 & 0.0 & 0.0 & 0.0 & 0.0 & 0.0 \\
\hline C22:0 (\%) & 0.0 & 0.2 & 0.0 & 0.0 & 0.0 & 0.0 & 0.0 & 0.0 \\
\hline C20:4 n-6 (\%) & 6.0 & 0.0 & 0.0 & 0.0 & 6.2 & 0.2 & 2.2 & 2.2 \\
\hline C22:1 n-9 (\%) & 0.0 & 0.0 & 0.0 & 0.0 & 0.0 & 0.1 & 0.7 & 0.0 \\
\hline C20:5 n-3 (\%) & 0.0 & 0.0 & 0.0 & 0.0 & 0.3 & 4.0 & 26.3 & 4.3 \\
\hline $\mathrm{C} 24: 0(\%)$ & 0.0 & 0.1 & 0.0 & 0.0 & 0.0 & 0.0 & 0.0 & 0.0 \\
\hline C22:4 n-6 (\%) & 0.2 & 0.0 & 0.0 & 0.0 & 0.3 & 0.2 & 1.6 & 0.0 \\
\hline C22:5 n-3 (\%) & 0.3 & 0.0 & 0.0 & 0.0 & 0.3 & 0.7 & 4.9 & 0.0 \\
\hline C22:6 n-3 (\%) & 3.7 & 0.0 & 0.0 & 0.0 & 3.9 & 3.7 & 26.2 & 5.8 \\
\hline
\end{tabular}

aPL, phospholipids; TG, triacylglycerols; DG, diacylglycerols; NEFA, non-esterified fatty acids.

heparinized (1000 IU/kg of body weight) through the right saphenous vein. After a rapid thoracotomy, the heart was quickly removed and immediately immersed in a large volume of cold $\left(4^{\circ} \mathrm{C}\right) \mathrm{Krebs}-\mathrm{Henseleit} \mathrm{buffer}$. The heart was then perfused at $37^{\circ} \mathrm{C}$ according to the Langendorff model (14), in absence of albumin, with a Krebs-Henseleit buffer composed of $\mathrm{NaCl}(129 \mathrm{mM}), \mathrm{KCl}(5.6 \mathrm{mM}), \mathrm{MgCl}_{2}$ (2.4 mM), $\mathrm{NaHCO}_{3}$ $(21 \mathrm{mM})$ and $\mathrm{CaCl}_{2}(2.5 \mathrm{mM})$. The perfusion fluid, continuously bubbled with carbogen $\left(95 \% \mathrm{O}_{2}-5 \% \mathrm{CO}_{2}\right)$, was supplemented with D-glucose $(11 \mathrm{mM})$ and sodium hexanoate $(0.5 \mathrm{mM})$ as a water-soluble source of fatty acid. The perfusion pressure was maintained at $74 \mathrm{mmHg}$ in order to insure a sufficient supply of perfusion medium into the coronary network. A fluid-filled latex balloon was inserted into the left ventricle via the left atrium to measure left ventricle pressure and heart rate (HR). The balloon was connected to a Capto SP-844 pressure transducer (ADInstruments, Colorado Springs, USA) through a short polyethylene catheter (PE190). Pressure signals were amplified with a bridge amplifier connected to a PowerLab data acquisition system (ADInstruments, PowerLab ${ }^{\circledR}$ ). The diastolic pressure was adjusted at a value close to $5 \mathrm{mmHg}$. The heart was then placed in a thermostabilized chamber allowing warming of the organ. All parameters of cardiac function were recorded and calculated with an appropriate software (ADInstruments, Chart ${ }^{\mathrm{TM}}$ software). The left ventricular developed pressure (LVDP) was calculated as the difference between systolic and diastolic pressures. The rate $\mathrm{x}$ pressure product (RPP), which is the product of left ventricular developed pressure times the heart rate, was used as an index of cardiac work.

The pulmonary artery was cannulated to collect the coronary effluent in a chamber in which a Clarke oxygen electrode (Instech, Plymouth, USA) was positioned. The electrode was connected to an oxygraph (Model 203, Instech) which allowed the continuous determination of venous oxygen pressure. Arterial oxygen pressure was also monitored continuously. Oxygen consumption was calculated according to the formula: $J \mathrm{O}_{2}=[(\mathrm{a}-\mathrm{v}) \times 1.53 \times \mathrm{Cf}] / \mathrm{HW}$ where $J \mathrm{O}_{2}$ is the oxygen consumption $[\mu \mathrm{mol} / \mathrm{min} / \mathrm{g}$ wet weight (w.w.) $]$, a the arterial oxygen pressure $(\mathrm{mmHg}), \mathrm{v}$ the venous oxygen pressure $(\mathrm{mmHg}), 1.53$ the oxygen dilution factor in the gassed Krebs-Henseleit buffer $(\mu \mathrm{mol} / \mathrm{mmHg} / \mathrm{l})(15)$, Cf the coronary flow $(1 / \mathrm{min})$ which was determined by measuring the volume of the coronary effluents collected over one minute, and HW the heart weight ( $\mathrm{g}$ w.w.). In Tables III and IV, Cf is expressed in $\mathrm{ml} / \mathrm{min} / \mathrm{g} \mathrm{W} . \mathrm{W}$. 
Table III. Pre-ischemic cardiac function.

\begin{tabular}{|c|c|c|c|c|c|c|}
\hline & \multicolumn{3}{|c|}{ Control rats } & \multicolumn{3}{|c|}{ n-3-depleted rats } \\
\hline & $\mathrm{NaCl} 0.9 \%$ & MCT:OO & MCT:FO & $\mathrm{NaCl} 0.9 \%$ & MCT:OO & MCT:FO \\
\hline LVDP & $\begin{array}{c}203.3 \pm 8.5^{a} \\
\quad(n=8)\end{array}$ & $\begin{array}{c}174.1 \pm 13.8 \\
(n=8)\end{array}$ & $\begin{array}{c}190.1 \pm 11.0 \\
(n=8)\end{array}$ & $\begin{array}{c}140.6 \pm 6.9^{a} \\
(n=15)\end{array}$ & $\begin{array}{c}147.5 \pm 8.0 \\
(n=13)\end{array}$ & $\begin{array}{c}128.8 \pm 9.3 \\
(n=6)\end{array}$ \\
\hline HR & $\begin{array}{c}254 \pm 11 \\
(n=8)\end{array}$ & $\begin{array}{c}264 \pm 12 \\
(n=8)\end{array}$ & $\begin{array}{c}254 \pm 8 \\
(n=8)\end{array}$ & $\begin{array}{l}274 \pm 9 \\
(n=15)\end{array}$ & $\begin{array}{c}277 \pm 14 \\
(n=13)\end{array}$ & $\begin{array}{c}275 \pm 8 \\
(n=6)\end{array}$ \\
\hline RPP & $\begin{array}{c}51.36 \pm 2.28^{a} \\
(n=8)\end{array}$ & $\begin{array}{c}45.86 \pm 3.93 \\
(n=8)\end{array}$ & $\begin{array}{c}48.18 \pm 2.87 \\
(n=8)\end{array}$ & $\begin{array}{c}38.90 \pm 2.50^{a} \\
\quad(n=15)\end{array}$ & $\begin{array}{c}40.78 \pm 4.21 \\
(n=13)\end{array}$ & $\begin{array}{c}35.47 \pm 2.85 \\
\quad(n=6)\end{array}$ \\
\hline $\mathrm{Cf}$ & $\begin{array}{c}10.3 \pm 0.9 \\
(n=8)\end{array}$ & $\begin{array}{c}10.4 \pm 1.4 \\
(n=8)\end{array}$ & $\begin{array}{c}7.8 \pm 0.4 \\
(n=8)\end{array}$ & $\begin{array}{l}9.5 \pm 0.3 \\
(n=15)\end{array}$ & $\begin{array}{c}9.8 \pm 0.6 \\
(n=13)\end{array}$ & $\begin{array}{c}10.6 \pm 0.8 \\
(n=6)\end{array}$ \\
\hline $\mathrm{JO}_{2}$ & $\begin{array}{c}5.97 \pm 0.48 \\
(n=7)\end{array}$ & $\begin{array}{c}6.54 \pm 0.88 \\
\quad(n=8)\end{array}$ & $\begin{array}{c}5.67 \pm 0.48 \\
(n=6)\end{array}$ & $\begin{array}{c}4.92 \pm 0.20 \\
(n=14)\end{array}$ & $\begin{array}{c}4.50 \pm 0.27 \\
(n=12)\end{array}$ & $\begin{array}{c}5.39 \pm 0.39 \\
\quad(n=6)\end{array}$ \\
\hline Jlactate & $\begin{array}{c}0.30 \pm 0.08 \\
(n=7)\end{array}$ & $\begin{array}{c}0.27 \pm 0.07 \\
\quad(n=8)\end{array}$ & $\begin{array}{c}0.26 \pm 0.05 \\
(n=8)\end{array}$ & $\begin{array}{c}0.20 \pm 0.05 \\
(n=11)\end{array}$ & $\begin{array}{c}0.23 \pm 0.05 \\
(n=10)\end{array}$ & $\begin{array}{c}0.44 \pm 0.12 \\
\quad(n=6)\end{array}$ \\
\hline
\end{tabular}

${ }^{\mathrm{a}}$ Control rats versus $\mathrm{n}$-3-depleted animals, $\mathrm{p}<0.05$. LVDP $(\mathrm{mmHg})$, left ventricular developed pressure; $\mathrm{HR}$ (bpm), heart rate; $\mathrm{RPP}(\mathrm{mmHg}$ $\left.\mathrm{x} 10^{3} / \mathrm{min}\right)$, rate $\mathrm{x}$ pressure product; $\mathrm{Cf}\left(\mathrm{ml} / \mathrm{min} / \mathrm{g}\right.$ wet weight), coronary flow; $\mathrm{JO}_{2}\left(\mu \mathrm{molO}_{2} / \mathrm{min} / \mathrm{g}\right.$ wet weight), oxygen consumption; Jactate $(\mu \mathrm{mol} / \mathrm{min} / \mathrm{g}$ wet weight), lactate flux. Values are means \pm SEM. Statistical comparisons were made using a one-way analysis of variance.

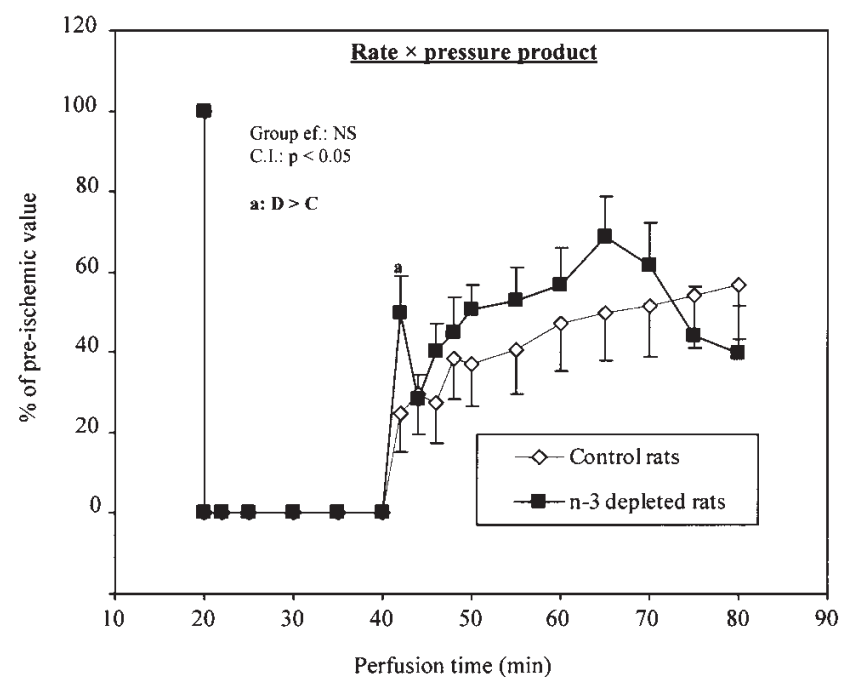

Figure 1. Influence of the n-3 PUFA deficiency on the rate $x$ pressure product recovery after a 20 -min zero-flow normothermic ischemia. The number of experiments was 8 and 13 for control and n-3-depleted rats, respectively. All animals were injected with the saline solution. Statistical comparisons were made using a repeated measurement analysis of variance. A comparison of the means was performed with a Fisher's LSD test. Group ef., effect of the n-3 PUFA deficient diet; C.I., cross-interaction; NS, not significant; a, significantly different by Fisher's LSD test (D, n-3 depleted rats; $\mathrm{C}$, control rats).

Experimental protocol. The hearts were perfused for $20 \mathrm{~min}$ under normoxic conditions. Thereafter, the thermostabilized chamber was filled with Krebs-Henseleit buffer maintained at $37^{\circ} \mathrm{C}$ and the hearts were subjected to a 20 -min zero-flow normothermic ischemia followed by a 40-min reperfusion. At the beginning of reperfusion, the thermostabilized chamber surrounding the heart was emptied. Aliquots of coronary effluents were collected just before ischemia and again at 2 , $4,6,8,10,15,20,25,30,35$ and 40 min post-ischemia, and stored at $-20^{\circ} \mathrm{C}$ for lactate determination.

Measurement of lactate release. Lactate concentration in the coronary effluents was determined spectrophotometrically (16). Lactate release from heart (Jlactate) was calculated as the product of lactate concentration in the effluents times coronary flow. It was expressed per g wet weight $(\mu \mathrm{mol} / \mathrm{min} /$ g w.w.).

Statistical analysis. The results are presented as mean values \pm SEM. Data describing the wet heart weight and cardiac function at the end of the stabilization period was subjected to a 1-way analysis of variance describing the effect of n-3 PUFA deficiency or preparation injection. Data of postischemic cardiac function was subjected to a repeatedmeasurement analysis of variance describing the effect of dietary n-3 PUFA deficiency or preparation injection (group ef., external factor), that of the reperfusion duration and the cross-interaction (C.I.) between both factors. When necessary, a comparison of the mean values was performed by a Fisher's LSD test. A Chi-2 test was used to determine the effects of an acute i.v. administration of the preparations on the number of hearts which had recovered a measurable RPP during reperfusion. A p-value $<0.05$ was considered as significant. All calculations were performed using the Statview software (Abacus Concepts, Cary, USA). 
Table IV. Post-ischemic cardiac function.

\begin{tabular}{|c|c|c|c|c|c|c|}
\hline & \multicolumn{3}{|c|}{ Control rats } & \multicolumn{3}{|c|}{ n-3-depleted rats } \\
\hline & $\mathrm{NaCl} 0.9 \%$ & MCT:OO & MCT:FO & $\mathrm{NaCl} 0.9 \%$ & MCT:OO & MCT:FO \\
\hline LVDP & $\begin{array}{c}1877.0 \pm 495.1 \\
(\mathrm{n}=8)\end{array}$ & $\begin{array}{c}2268.9 \pm 482.7 \\
(n=8)\end{array}$ & $\begin{array}{c}2475.7 \pm 449.8 \\
(n=8)\end{array}$ & $\begin{array}{l}1846.8 \pm 244.1^{a} \\
\quad(n=15)\end{array}$ & $\begin{array}{c}2725.3 \pm 252.3^{a} \\
(n=13)\end{array}$ & $\begin{array}{c}2889.8 \pm 759.6^{a} \\
\quad(n=6)\end{array}$ \\
\hline HR & $\begin{array}{c}3651.8 \pm 635.5 \\
\quad(n=8)\end{array}$ & $\begin{array}{c}3593.6 \pm 598.5 \\
(n=8)\end{array}$ & $\begin{array}{c}3529.4 \pm 351.9 \\
(n=8)\end{array}$ & $\begin{array}{l}4019.7 \pm 656.7 \\
\quad(n=15)\end{array}$ & $\begin{array}{c}4607.6 \pm 594.0 \\
\quad(n=13)\end{array}$ & $\begin{array}{c}5629.6 \pm 1481.5 \\
(\mathrm{n}=6)\end{array}$ \\
\hline RPP & $\begin{array}{c}1729.9 \pm 418.8^{b} \\
(n=8)\end{array}$ & $\begin{array}{c}2150.6 \pm 454.3 \\
(n=8)\end{array}$ & $\begin{array}{c}2439.2 \pm 476.2 \\
\quad(n=8)\end{array}$ & $\begin{array}{c}1894.0 \pm 263.0^{\mathrm{ab}} \\
\quad(\mathrm{n}=15)\end{array}$ & $\begin{array}{c}2721.1 \pm 174.9^{a} \\
(n=13)\end{array}$ & $\begin{array}{c}3551.8 \pm 658.6^{a} \\
(n=6)\end{array}$ \\
\hline $\mathrm{Cf}$ & $\begin{array}{c}3684.6 \pm 134.1 \\
\quad(n=8)\end{array}$ & $\begin{array}{c}3621.6 \pm 129.7 \\
(n=8)\end{array}$ & $\begin{array}{c}3579.3 \pm 70.1 \\
\quad(n=8)\end{array}$ & $\begin{array}{c}3405.1 \pm 206.6^{c} \\
\quad(n=15)\end{array}$ & $\begin{array}{c}3482.4 \pm 94.5^{c} \\
\quad(n=13)\end{array}$ & $\begin{array}{c}3827.9 \pm 257.0^{\mathrm{c}} \\
(\mathrm{n}=6)\end{array}$ \\
\hline $\mathrm{JO}_{2}$ & $\begin{array}{c}4026.7 \pm 687.9 \\
(n=7)\end{array}$ & $\begin{array}{c}4302.2 \pm 97.2 \\
\quad(n=8)\end{array}$ & $\begin{array}{c}4304.7 \pm 88.9 \\
\quad(n=6)\end{array}$ & $\begin{array}{l}4216.3 \pm 337.1^{c} \\
\quad(n=14)\end{array}$ & $\begin{array}{c}4241.2 \pm 180.3^{c} \\
(n=12)\end{array}$ & $\begin{array}{c}5617.1 \pm 517.9^{c} \\
\quad(n=6)\end{array}$ \\
\hline Jlactate & $\begin{array}{c}19.8 \pm 3.0^{c} \\
(n=7)\end{array}$ & $\begin{array}{c}14.4 \pm 1.5^{\mathrm{c}} \\
(\mathrm{n}=8)\end{array}$ & $\begin{array}{c}12.6 \pm 1.5^{c} \\
(n=8)\end{array}$ & $\begin{array}{c}23.6 \pm 7.8 \\
(n=11)\end{array}$ & $\begin{array}{c}35.0 \pm 10.1 \\
\quad(n=10)\end{array}$ & $\begin{array}{l}21.2 \pm 1.8 \\
\quad(n=6)\end{array}$ \\
\hline
\end{tabular}

${ }^{\mathrm{a}}$ Group effect, ${ }^{\mathrm{b}}$ cross-interaction, ${ }^{\mathrm{c}}$ group effect and cross-interaction, $\mathrm{p}<0.05$. LVDP (mmHg), left ventricular developed pressure; HR (bpm), heart rate; RPP ( $\left.\mathrm{mmHg} \times 10^{3} / \mathrm{min}\right)$, rate x pressure product; $\mathrm{Cf}\left(\mathrm{ml} / \mathrm{min} / \mathrm{g}\right.$ wet weight), coronary flow; $\mathrm{JO}_{2}\left(\mu \mathrm{molO}{ }_{2} / \mathrm{min} / \mathrm{g}\right.$ wet weight), oxygen consumption; Jlactate $(\mu \mathrm{mol} / \mathrm{min} / \mathrm{g}$ wet weight), lactate flux. Values are means \pm SEM and represent the area under each curve over the 40-min reperfusion period. Statistical comparisons shown in this table correspond to those represented in the figures. Results with pooled data are not represented.

\section{Results}

Animal model. At about the same age (14 weeks), body weight of $n$-3-depleted rats was higher than that of control rats $(476 \pm 8 \mathrm{~g}, \mathrm{n}=33$ versus $432 \pm 8 \mathrm{~g}, \mathrm{n}=24 ; \mathrm{p}<0.001)$. In the former animals, heart weight measured after ischemiareperfusion (I/R) was also significantly higher than that in control rats $(2.46 \pm 0.07 \mathrm{~g}, \mathrm{n}=20$, in $\mathrm{n}$-3-depleted rats versus $1.95 \pm 0.06 \mathrm{~g} \mathrm{w} . \mathrm{w} ., \mathrm{n}=24$, in control rats; $\mathrm{p}<0.001)$. The ratio between body weight and heart weight in $n$-3-depleted rats was significantly lower than that in control rats $(200.70 \pm 5.42$, $\mathrm{n}=20$, in $\mathrm{n}$-3-depleted versus $224.15 \pm 5.38, \mathrm{n}=24$, in control rats; $\mathrm{p}<0.01)$.

Pre-ischemic cardiac function. Data on cardiac function at the end of the 20-min stabilization period is documented in Table III. After saline injection, LVDP was significantly lower in the n-3-depleted rats than in control animals (-44\%). HR was not affected by n-3 PUFA deficiency. As a consequence the RPP, which is considered a reliable index of the mechanical work, was significantly reduced in the n-3-depleted rats $(-25 \%)$. There was no difference in $\mathrm{Cf}, \mathrm{JO}_{2}$ and Jlactate between both groups. However, the calculation of the ratio between RPP and $\mathrm{JO}_{2}$ indicated that cardiac efficiency was significantly $(\mathrm{p}<0.05)$ decreased in the $\mathrm{n}$-3-depleted rats $\left(5.34 \pm 0.63 \mathrm{mmHg} \times 10^{3} / \mu \mathrm{molO}_{2} / \mathrm{g}, \mathrm{n}=14\right)$ versus control animals $\left(9.50 \pm 1.21 \mathrm{mmHg}^{2} 10^{3} / \mu \mathrm{molO}_{2} / \mathrm{g}, \mathrm{n}=7\right)$. In the rats injected with MCT:FO and MCT:OO preparations, cardiac function was, as a rule, not significantly different from that in saline-injected animals. Nevertheless, prior injection of the
MCT:FO preparation lowered $(\mathrm{p}<0.025) \mathrm{Cf}$ in control rats. Such was not the case in n-3-depleted rats.

Because of the difference of cardiac function between control and n-3-depleted animals, all the results obtained during reperfusion were expressed as a percentage of the paired pre-ischemic value.

Post-ischemic cardiac function. The effect of I/R was first evaluated in rats injected with saline (Fig. 1). During reperfusion, the recovery of RPP did not significantly differ between $\mathrm{n}$-3-depleted and control rats. However, in addition to a higher value for the first measurement during reperfusion, the $n-3$ PUFA deficient diet had an obvious effect from the 25th min of reperfusion onwards. In the n-3-depleted group, RPP progressively decreased between min 25 and 40 of reperfusion, whereas it remained stable in the control group (ANOVA, 'lipid profile $\mathrm{x}$ time' interaction, $\mathrm{p}<0.05)$. The number of hearts with a not null recovery of mechanical activity after ischemia was 7 out of 8 in the control rats and 12 out of 15 in the n-3-depleted rats. Results for LVDP, HR, Cf, $\mathrm{JO}_{2}$ and Jactate revealed no significant difference between control and n-3-depleted animals. To illustrate these results, the area under each curve was determined over the 40-min reperfusion period for all parameters (Table IV).

The recovery of RPP did not differ between control rats injected with either MCT:FO or the MCT:OO preparation (Fig. 2A). A similar response pattern was observed for LVDP, $\mathrm{HR}, \mathrm{Cf}$ and $\mathrm{JO}_{2}$ (Table IV). However, since no difference in RPP was observed between animals injected with MCT:FO or MCT:OO, data obtained with both preparations were pooled. 

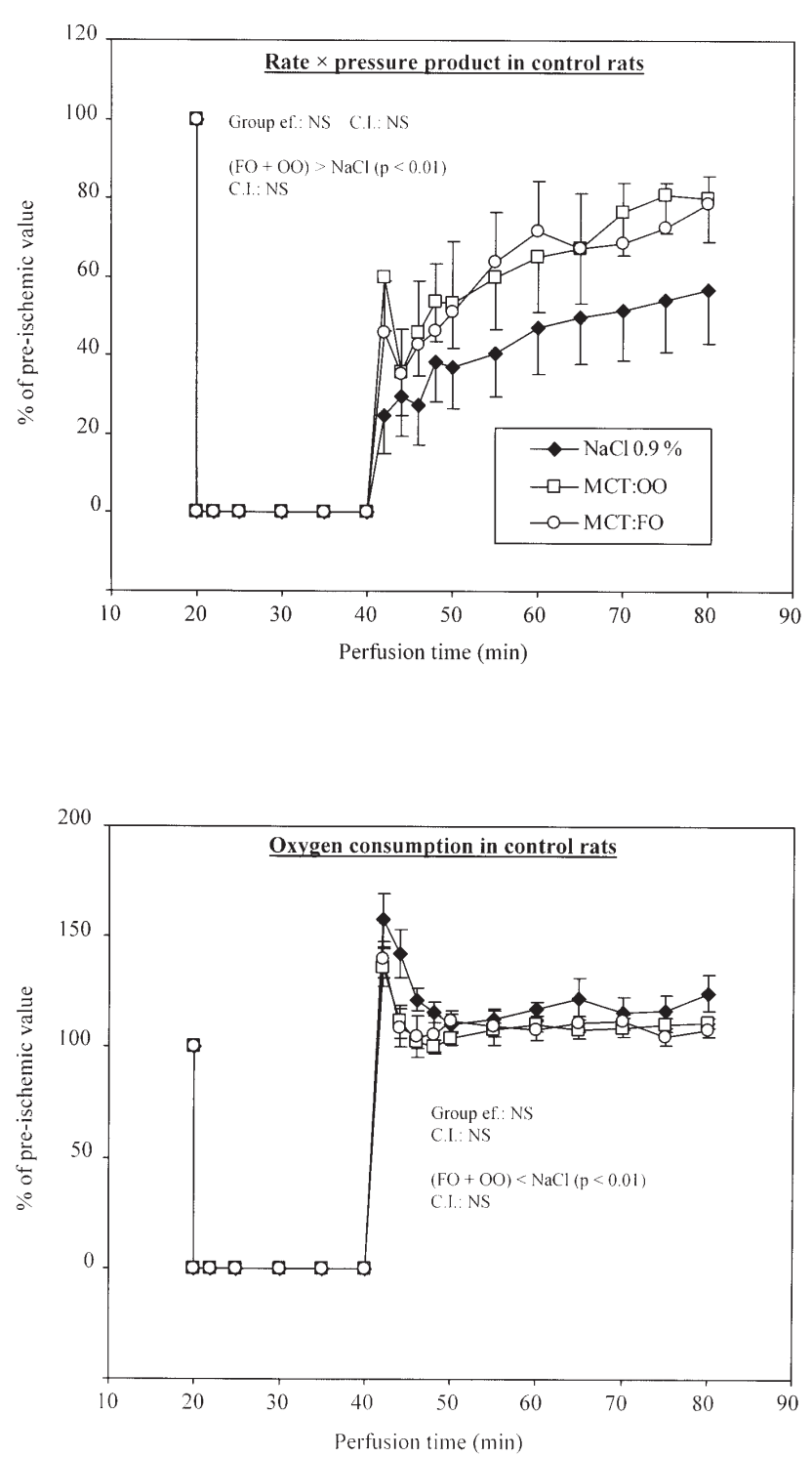

Figure 2. Effect of the acute injection of the MCT:FO and MCT:OO preparations on the rate $\mathrm{x}$ pressure product (A) and oxygen consumption (B) recovery after a 20 -min zero-flow normothermic ischemia in control rats. The number of experiments was 8 per treatment for the rate $\mathrm{x}$ pressure product, 7 and 6 for MCT:OO and MCT:FO respectively for oxygen consumption. Statistical comparisons were made using a repeated measurement analysis of variance. Group ef., effect of the acute injection; C.I., cross-interaction; NS, not significant. (FO + OO), the RPP and oxygen consumption data during reperfusion obtained with the MCT:FO and MCT:OO preparations were pooled.

Under these conditions, RPP during reperfusion was significantly higher in rats injected with the lipid preparations $(+22 \%$ at the end of the reperfusion) than in those injected with saline. For myocardial oxygen consumption, values were significantly lower in animals injected with lipid preparations $(-15 \%)$ than in those injected with saline (Fig. 2B). Jlactate was significantly lower in rats injected with MCT:FO than in those injected with MCT:OO or saline (Fig. 3). The difference failed to achieve significance $(\mathrm{p}=0.06)$ between animals injected with MCT:OO and those injected with saline. Nevertheless, when pooling together the data obtained with MCT:FO and MCT:OO preparations, Jlactate during

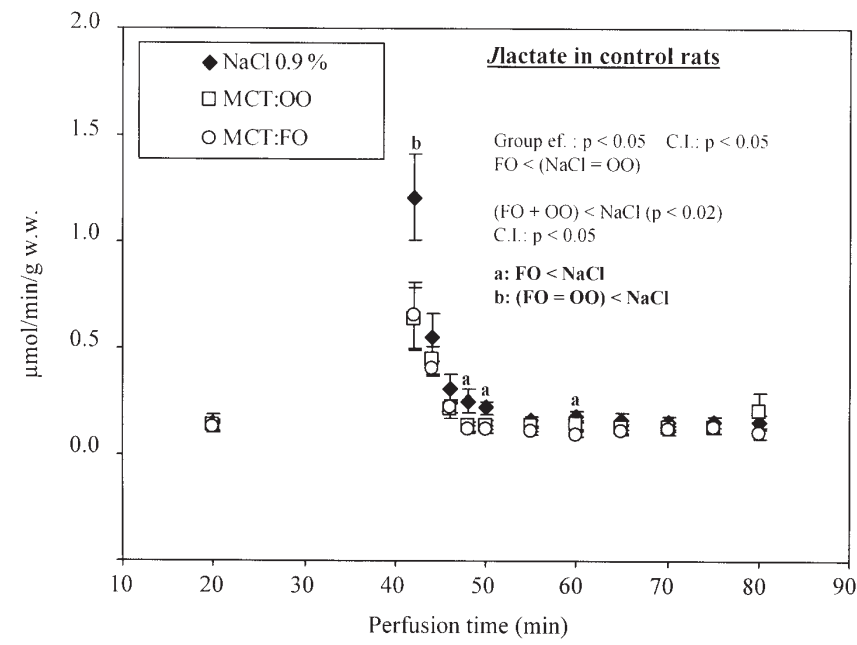

Figure 3. Effect of the acute administration of the MCT:FO and MCT:OO preparations on the lactate release (Jlactate) after ischemia in control rats. The number of experiments was 7 for saline solution, and 8 for MCT:OO and MCT:FO preparations. Statistical comparisons were made using a repeated measurement analysis of variance. A comparison of the means was performed with a Fisher's LSD test. Group ef., effect of the preparation; C.I., cross-interaction; a,b, significantly different by Fisher's LSD test. (FO + OO), the Jlactate data during reperfusion obtained with the MCT:FO and MCT:OO preparations were pooled.

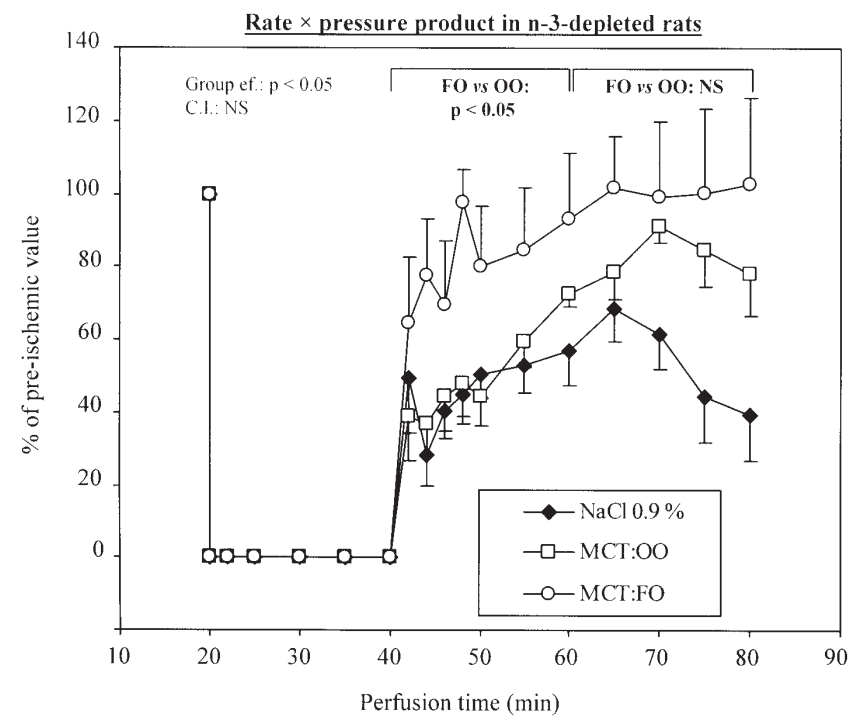

Figure 4. Effect of the acute injection of the MCT:FO and MCT:OO preparations on the rate $x$ pressure product recovery after a 20-min zeroflow normothermic ischemia in $n$-3-depleted rats. The number of experiments was 15,13 and 6 for n-3-depleted animals injected with the saline solution, MCT:OO and MCT:FO preparations, respectively. Statistical comparisons were made using a repeated measurement analysis of variance. Group ef., effect of the acute injection; C.I., cross-interaction; NS, not significant. The effect of the MCT:FO and MCT:OO preparations on the RPP were compared during the first and the last 20-min reperfusion period using a repeated measurement analysis of variance.

reperfusion was significantly decreased as compared to that of animals administered saline.

An acute injection of lipid preparation in n-3-depleted rats significantly increased RPP during the 40-min reperfusion period by comparison to saline injection. The difference between MCT:FO and MCT:OO injections did not reach 

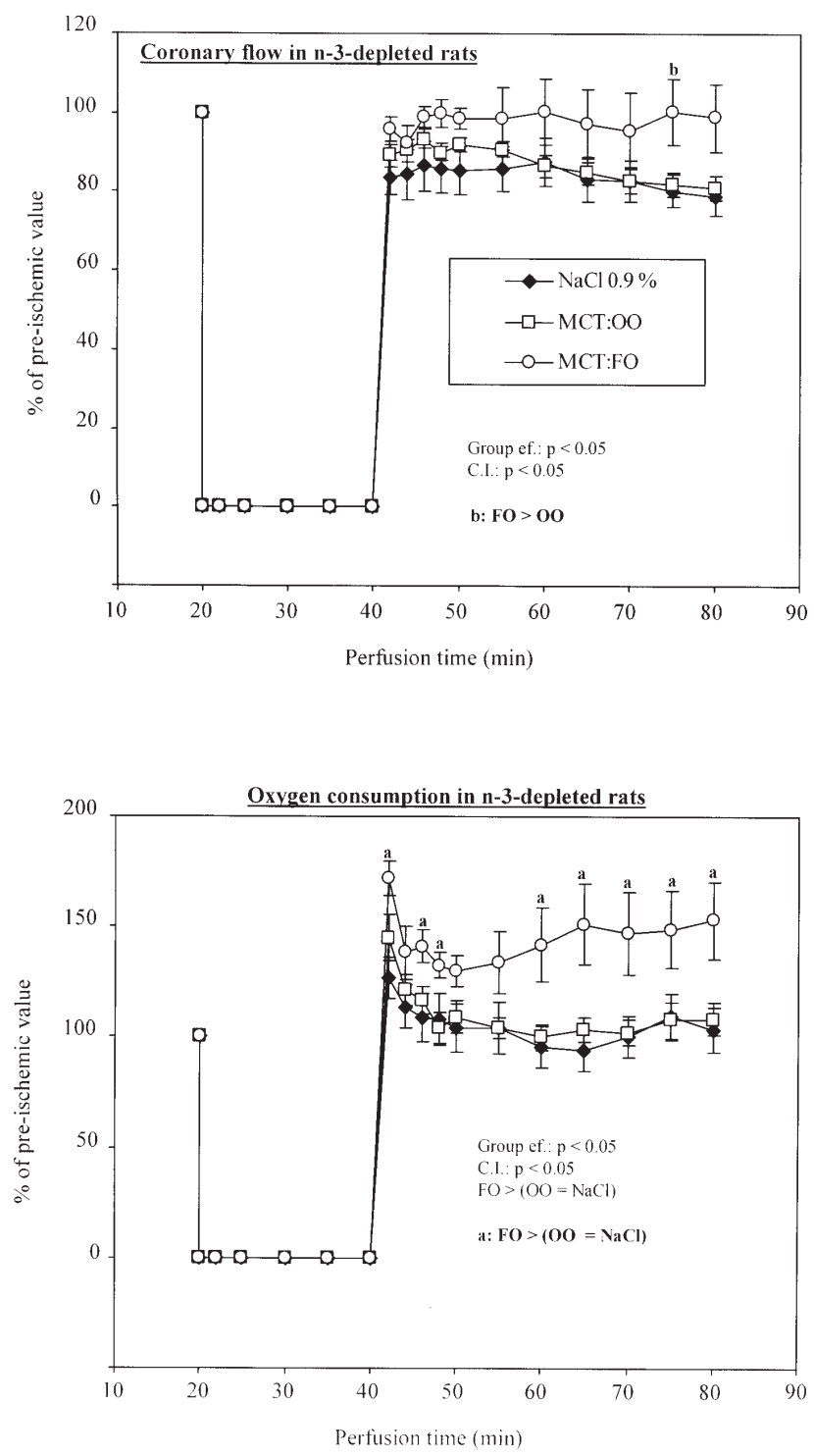

Figure 5. Effect of the acute injection of the MCT:FO and MCT:OO preparations on the coronary flow (A) and oxygen consumption (B) recovery after ischemia in $n-3$-depleted animals. The number of experiments for the coronary flow was 15,13 and 6 for n-3-depleted animals injected with the saline solution, MCT:OO and MCT:FO preparations, respectively. For the oxygen consumption, the number of experiments was 14, 12 and 6 for $n$-3-depleted animals injected with the saline solution, MCT:OO and MCT:FO preparations respectively. Statistical comparisons were made using a repeated measurement analysis of variance. A comparison of the means was performed with a Fisher's LSD test. Group ef., effect of the acute injection; C.I., cross-interaction; a,b, significantly different by Fisher's LSD test.

statistical significance ( $\mathrm{p}=0.07$, Fig. 4 ) when expressed for the whole $40 \mathrm{~min}$ reperfusion period. However, in the first 20-min of reperfusion, RPP measured in hearts of animals injected with MCT:FO was higher than that in hearts of animals injected with MCT:OO ( $\mathrm{p}<0.05)$. Furthermore, the number of hearts recovering a measurable RPP was higher after MCT:FO injection as compared to saline ( $\mathrm{p}<0.05$, Chi- 2 test).

The results of LVDP and HR are shown in Table IV. LVDP recovery was enhanced in n-3-depleted animals injected with MCT:OO preparation as compared to those injected with saline $(\mathrm{p}<0.05)$. The mean values for LVDP recovery were
A comparable between MCT:OO- and MCT:FO-injected animals. HR recovery was similar in the 3 groups. Cf and $\mathrm{JO}_{2}$ were significantly increased during the 40-min reperfusion period after MCT:FO- as compared to saline injection (Figs. 5A and B). There was no difference between the values obtained after MCT:OO versus saline injection. Jlactate was not affected by the injection of lipid preparations (Table IV).

\section{Discussion}

Effect of n-3 PUFA deficiency on basal cardiac function and responsiveness of the heart after ischemia. A first important information from this study is that the n-3 PUFA deficient diet significantly depresses cardiac function at the end of the 20-min stabilization period. Both LVDP and RPP were reduced, as well as the ratio between RPP and $\mathrm{JO}_{2}$ which is considered as a reliable index of cardiac metabolic efficiency. Several possibilities could be considered to explain this effect. Firstly, the n-3 PUFA deficient diet may change the balance B between carbohydrate and fatty acid oxidation towards a higher contribution of fatty acids for ATP production. A decrease in glucose uptake was observed in the brain of a n-3 PUFA deficient rats (17). However, this is unlikely to account to any great extent for the above mentioned change in the ratio between RPP and $\mathrm{JO}_{2}$, because of the close ATP/O ratio between carbohydrate (3.0) and fatty acid (2.8) oxidation. Secondly, the n-3 PUFA deficient diet may modify the yield of oxidative phosphorylation pathway independently of substrate utilization. In other words, the number of ATP moles produced per $\mathrm{O}_{2}$ consumed (energy yield of $\mathrm{O}_{2}$ ) could be lower in n-3-depleted versus control animals, irrespective of the substrate used, as a result of wasting processes. Studies in both isolated mitochondria and intact cells have shown that n-3 PUFA deficiency causes an increase in proton permeability of the inner mitochondrial membrane, similar to that caused by the classical protonophore 2,4-dinitrophenol (18). Thirdly, the n-3 PUFA deficient diet could alter energy transfer from mitochondria to sites of energy utilization through an effect on phosphotransfer kinases (19).

During reperfusion, the mean recovery of RPP in hearts of $n$-3-deficient rats decreased at the end of reperfusion, whereas hearts from control animals could maintain sustained RPP values throughout reperfusion. These results suggest that the n-3 PUFA deficient diet may increase the severity of cellular damage after zero-flow ischemia in isolated perfused rat hearts. In this respect, Nasa et al have shown that deprivation of fish oil from the diet enhances the susceptibility of cardiomyocytes to hypoxic injury (20). The mechanisms by which the n-3 PUFA deficient diet could increase the severity of myocardial ischemia are not clear. However, an enrichment of membrane phospholipids with n-3 PUFA was shown to alter the properties of key enzymes and to modify calcium homeostasis during I/R (21).

Effect of an acute i.v. injection of MCT:FO and MCT:OO preparations on cardiac function recovery post-ischemia in control and n-3-depleted animals. The control MCT:OO differed from the test MCT:FO preparation by the presence of triolein and the absence of n-3 PUFA. Both preparations had a similar $\alpha$-tocopherol content. 
In control animals, there was no difference in RPP recovery between those injected with saline or with one or the other lipid preparation. Nevertheless, when RPP values obtained with MCT:FO and MCT:OO (which were not different from one another) were pooled, RPP recovery was faster in hearts of animals injected with these preparations as compared to those injected with saline. The improvement of RPP recovery could be due to the presence of $\alpha$-tocopherol, a free radical scavenger, in both MCT:FO and MCT:OO preparations. During the first minutes of reperfusion, production of reactive oxygen species occurs at a high magnitude and plays a crucial role in molecular and cellular damage (22). Furthermore, in vivo and ex vivo studies have suggested that administration of Trolox (a hydrophilic analogue of $\alpha$-tocopherol) may enhance cardiac function recovery after ischemia $(23,24)$.

In control rats, the acute injection of lipid preparations significantly decreased Jlactate during reperfusion. In most clinical situations of post-ischemic reperfusion, the heart is exposed to high levels of fatty acids (25). Reperfusion of reversibly injured ischemic myocardium results in a rapid recovery of fatty acid oxidation with rates often exceeding pre-ischemic levels (26). This high rate of fatty acid oxidation inhibits glucose oxidation to a much greater extent than nonoxidative glycolysis, resulting in a so-called uncoupling between the rates of glycolysis and glucose oxidation (27). When the rate of non-oxidative glycolysis is high, this potentially important source of $\mathrm{H}^{+}$production during reperfusion could contribute to acidosis and calcium accumulation and ultimately to an impaired recovery of cardiac function (27). As a result, cardiac function recovery could be impaired. Therefore, we propose that decrease in Jlactate observed during reperfusion in hearts from rats injected with the lipid preparations to be beneficial for RPP recovery through an improvement of glucose metabolism coupling.

In n-3-depleted animals, the acute i.v. injection of the MCT:FO and MCT:OO preparations improved cardiac function recovery following a 20-min total normothermic ischemia. In this respect, administration of MCT:FO led to superior results during the first $20 \mathrm{~min}$ of reperfusion than MCT:OO injection. Furthermore, RPP decreased at the end of the reperfusion period in saline and MCT:OO groups, whereas it remained stable in the MCT:FO group. In a dog model of post-myocardial infarction, Billman et al have demonstrated the potential for a $1 \mathrm{~h}$ infusion of pure $\mathrm{n}-3$ PUFAs to prevent ischemia-induced ventricular fibrillation (28). Cardiac rhythm could not be closely monitored in the present study but the drop of RPP observed in the saline and MCT:OO groups was associated with periods of null developed pressure, suggesting either tachycardia or fibrillation (data not shown). The mechanism of action of the MCT:FO emulsion can be related to the incorporation of EPA and DHA in (or between) membrane phospholipids. In comparable experimental conditions, the content of EPA and DHA in heart phospholipids of rats injected $60 \mathrm{~min}$ before sacrifice with MCT:FO represented 119.3 $\pm 5.2 \%(n=12, p<0.005)$ of the mean values found in animals injected with MCT:OO $(100.0 \pm 3.4 \%, \mathrm{n}=12)$ (unpublished data).

In parallel to the enhanced recovery of mechanical activity in n-3-depleted rats injected with MCT:FO, Cf and $\mathrm{JO}_{2}$ recovery was significantly increased during the 40-min reperfusion as compared to values measured in the saline group. An increase of post-ischemic myocardial blood flow was reported in animals supplemented with fish oil, and associated to an improved NO synthesis (29). The increase of myocardial oxygen consumption can be related to RPP recovery. However, a marked uncoupling between myocardial oxygen consumption and cardiac work was observed, mainly in the MCT:OO and saline groups. Several mechanisms can contribute to this mismatch, including mitochondrial dysfunction (30), heterogeneous microcirculation (31), desynchronized contractions (32), altered excitationcontraction coupling (33) and/or increased energy demand for contractile work (31). A shift toward increased utilization of fatty acids could also be considered (25).

In conclusion, n-3 PUFA deficiency in rats was shown to decrease cardiac efficiency during the pre-ischemic period and to impair recovery of cardiac function after a zero-flow ischemia in isolated perfused rat hearts, suggesting an increased severity of myocardial ischemia. A bolus i.v. injection of the lipid preparation MCT:FO 60-min before heart removal led to an enrichment of heart phospholipids with n-3 PUFA, and to a significant improvement of cardiac function recovery. The potential to rapidly correct n-3 PUFA deficiency may offer interesting perspectives in the management of acute ischemic accidents such as myocardial infarction and stroke.

\section{Acknowledgements}

The lipid preparations were manufactured and kindly provided by B. Braun Melsungen (Germany). The study was supported by a grant from the Région de Bruxelles-Capitale (BCBR246/2410) to Target Hit sa (Brussels, Belgium). S.P. benefited from a Lavoisier grant from the French Foreign Office (Ministère Français des Affaires Étrangères).

\section{References}

1. Murray JL and Lopez AD: Alternative projections of mortality and disability by cause 1990-2020: Global Burden of Disease Study. Lancet 349: 1498-1504, 2000.

2. Dyerberg J, Bang HO, Stoffersen E, Moncada S and Vane JR: Eicosapentaenoic acid and prevention of thrombosis and atherosclerosis? Lancet 2: 117-119, 1978.

3. Tamura Y, Hirai A, Terano T, Takenaga M, Saitoh H, Tahara K and Yoshida S: Clinical and epidemiological studies of eicosapentaenoic acid (EPA) in Japan. Prog Lipid Res 25: 461-466, 1986.

4. Michels KB and Schulze MB: Can dietary patterns help us detect diet-disease associations? Nutr Res Rev 18: 241-248 2005.

5. Gruppo Italiano per lo Studio della Sopravvi-venza nell'Infarto miocardico. Dietary supplementation with $n-3$ polyunsaturated fatty acids and vitamin E after myocardial infarction: results of the GISSI-Prevenzione trial. Lancet 354: 447-455, 1999.

6. Burr ML: Fish food, fish oil and cardiovascular disease. Clin Exp Hypertens A14: 181-192, 1992.

7. Simopoulos AP: The importance of the ratio of omega-6/ omega-3 essential fatty acids. Biomed Pharmacother 56: 365-379, 2002 .

8. Pound EM, Kang JX and Leaf A: Partitioning of polyunsaturated fatty acids, which prevent cardiac arrhythmias, into phospholipid cell membranes. J Lipid Res 42: 346-351, 2001.

9. Jude S, Roger S, Martel E, Besson P, Richard S, Bougnoux P, Champeroux P and Le Guennec JY: Dietary long-chain omega-3 fatty acids of marine origin: A comparison of their protective effects on coronary heart disease and breast cancers. Prog Biophys Mol Biol 90: 299-325, 2006. 
10. Demaison L and Moreau D: Dietary n-3 polyunsaturated fatty acids and coronary heart disease-related mortality: a possible mech-anism of action. Cell Mol Life Sci 59: 463-477, 2002.

11. Schrepf R, Limmert T, Weber PC, Theisen K and Sellmayer A: Immediate effects of n-3 fatty acid infusion on the induction of sustained ventricular tachycardia. Lancet 363: 1441-1442, 2004.

12. Portois L, Deckelbaum RJ, Malaisse WJ and Carpentier YA: Accumulation rapide d'eicosapentaenoate dans les phospholipides cellulaires après injection intraveineuse d'une émulsion d'huile de poisson et de triglycérides à chaîne moyenne à des sujets normaux. Nutr Clin Métab 18: S53, 2004.

13. Acar N, Chardigny JM, Bonhomme B, Almanza S, Doly M and Sebedio JL: Long-term intake of trans $(n-3)$ polyunsaturated fatty acids reduces the b-wave amplitude of electroretinograms in rats. J Nutr 132: 3151-3154, 2002.

14. Langendorff O: Untersuchungern am überlebden Saügertierherzen. Pflügers Arch 61: 291-352, 1895.

15. Hak JB, Van Beek JH, Van Wijhe MH and Westerhof N: Influence of temperature on the response time of mitochondrial oxygen consumption in isolated rabbit heart. J Physiol 447: 17-31, 1992.

16. Bergmeyer HU: Methods of enzymatic analysis. 3rd edition. London, pp1464-1468, 1974.

17. Ximenes Da Silva A, Lavialle F, Gendrot G, Guesnet P, Alessandri JM and Lavialle M: Glucose transport and utilization are altered in the brain of rats deficient in $n-3$ polyunsaturated fatty acids. J Neurochem 81: 1328-1337, 2002.

18. Piquet MA, Fontaine E, Sibille B, Filippi C, Keriel C and Leverve XM: Uncoupling effect of polyunsaturated fatty acid deficiency in isolated rat hepatocytes: effect on glycerol metabolism. Biochem J 317: 667-674, 1996.

19. Vatner DE and Ingwall JS: Effects of moderate pressure overload cardiac hypertrophy on the distribution of creatine kinase isozymes. Proc Soc Exp Biol Med 175: 5-9, 1984.

20. Nasa Y, Hayashi M, Sasaki H, Hayashi J and Takeo S: Long-term supplementation with eicosapentaenoic acid salvages cardiomyocytes from hypoxia/reoxygenation-induced injury in rats fed with fish-oil deprived diet. Jpn J Pharmacol 77: 137-146, 1998. 1998

21. Demaison L, Moreau D, Vergely-Vandriesse C, Gregoire S, Degois M and Rochette L: Effects of dietary polyunsaturated fatty acids and hepatic steatosis on the functioning of isolated working rat heart under normoxic conditions and during postischemic reperfusion. Mol Cell Biochem 224: 103-116, 2001.
22. McCord JM: Oxygen-derived free radicals in postischemic tissue injury. N Engl J Med 312: 159-163, 312.

23. Molyneux CA, Glyn MC and Ward BJ: Oxidative stress and cardiac microvascular structure in ischemia and reperfusion: the protective effect of antioxidant vitamins. Microvasc Res 64: 265-277, 2002.

24. Sagach VF, Scrosati M, Fielding J, Rossoni G, Galli C and Visioli F: The water-soluble vitamin $\mathrm{E}$ analogue Trolox protects against ischaemia/reperfusion damage in vitro and ex vivo. A comparison with vitamin E. Pharmacol Res 45: 435-439, 2002.

25. Lopaschuk GD, Belke DD, Gamble J, Itoi T and Schonekess BO: Regulation of fatty acid oxidation in the mammalian heart in health and disease. Biochim Biophys Acta 1213: 263-276, 1994.

26. Liedtke AJ: Lipid burden in ischemic myocardium. J Mol Cell Cardiol 20: 65-74, 1988.

27. Liu B, Clanachan AS, Schulz R and Lopaschuk GD: Cardiac efficiency is improved after ischemia by altering both the source and fate of protons. Circ Res 79: 940-948, 1996.

28. Billman GE, Kang JX and Leaf A: Prevention of ischemiainduced cardiac sudden death by $n-3$ polyunsaturated fatty acids in dogs. Lipids 32: 1161-1168, 1997.

29. Force T, Malis CD, Guerrero JL, Varadarajan GS, Bonventre JV, Weber PC and Leaf A: n-3 fatty acids increase postischemic blood flow but do not reduce myocardial necrosis. Am J Physiol 257: H1204-H1210, 1989.

30. Demaison L, Sergiel JP, Moreau D and Grynberg A: Influence of the phospholipid n-6/n-3 polyunsaturated fatty acid ratio on the mitochondrial oxidative metabolism before and after myocardial ischemia. Biochim Biophys Acta 1227: 53-59, 1994.

31. Laxson DD, Homans DC, Dai XZ, Sublett E and Bache RJ: Oxygen consumption and coronary reactivity in postischemic myocardium. Circ Res 64: 9-20, 1989.

32. Krukenkamp IB, Silverman NA, Sorlie D, Pridjian A, Feinberg H and Levitsky S: Characterization of postischemic myocardial oxygen utilization. Circulation 74: III125-129, 1986.

33. Furukawa S, Bavaria JE, Kreiner G and Edmunds LH Jr: Relationship between total mechanical energy and oxygen consumption in the stunned myocardium. Ann Thorac Surg 49: 543-548, 1990. 